\title{
Layer-by-Layer Approach to Bio-Inspired, Large-Area Formation of Silica Thin Films
}

\author{
Sung Ho Yang, Ji Hun Park, and Insung S. Choi \\ Deparment of Chemistry. KHIST. Daejeon 305-701. Korea. 'E-mail: ischoiaakaistack \\ Received July 15, 2009, Accepted August 3, 2009
}

Key Words: Biomimicry, Layer-by-laỵer. Polyelectrolytes. Silica. Silicification

The controlled fabrication of inorganic thin films with low cost and large area-uniformity is a promising route to the realization of various applied areas including biomedicine. biosensors. ${ }^{2}$ heterogeneous catalysis. ${ }^{3}$ cell culture, ${ }^{4}$ and wettability. "Bio-inspired methods. utilizing peptides and proteins found in nature or biomimetic polymers as catalytic templates. have been suggested as an alternative to conventional fabrication methods such as electrodeposition chemical deposition. and lithography; they are considered advantageous for facilely generating and controlling inorganic thin films under mild conditions (at near netutral $\mathrm{pH}$ and room temperature) by mimicking the biological reaction processes that occur under physiological conditions."

The initial attempts focused on silicification (silica formation) found in diatoms and glass sponges. and the catalytic templates, either natural or synthetic. have been introduced on substrate surfaces by simple ply sisorption ${ }^{8}$ or surface-initiated polymerization. Layer-by-layer (LbL) deposition processes have recently been suggested as a bio-friendly method for introducing catalytic templates on substrate surfaces: a combination of bio-friendly LbL processes with the bio-inspired method for generating inorganic films that is intrinsically biocompatible would widen the applications to the ones employing biological entities, such as living cells. Ball $e$ t al. produced silica/polyamine composite films by alternately depositing positively charged polyamine and negatively charged silicic acid that was a silicification precursor. ${ }^{11}$ We demonstrated the bio-inspired formation of silica micropatterns. where all the processes were performed in the aqueous solution under mild conditions. by taking advantage of the LbL technique. " In addition to potential biocompatibility. the LbL processes proved simple to perform and suitable for large-area fabrication. ${ }^{13}$ In this note. we report the bio-inspired formation and characterization of silica thin films that were continuously uniform at least over the centimeter scale. where LbL processes were utilized to deposit catalytic templates onto carbosylic acid-terminated self-assembled monolayers (SAMs) on gold.

Poly (dially ldimethylammonium chloride) (PDADMA) was selected as a catalytic template for the silicification. based on the reports that polyamine-containing. cationic peptides. named silaffins, played important roles in biological silica formation of diatoms and poly'(sodium 4-sty renesulfonate) (PSS) was used as the counter polyelectrolyte in the LbL processes. The carboxylic acid-terminated SAMs were formed on gold by using 11-mercaptoundecanoic acid (MUA). ${ }^{1+}$ The MUA-coated substrate $\left(6 \times+\mathrm{cm}^{2}\right)$ was alternately immersed in aqueous
$\mathrm{NaCl}$ solutions of PDADMA and PSS for 5 min each. and the thickness of the filnts was varied by the number of the immersion steps. The LbL processes were started with PDADMA for achieving electrostatic interactions with carboxylate groups at the substrate surface and also finished with PDADMA for doing catalytic interactions with silicic acid derivatives at the outer interface.

We prepared three different samples of PDADMA/PSS polyelectrolyte multilayer (PEM) films (6/5.11/10. and 16/15) on the MUA SAMs (the three PEM films were denoted as $\mathrm{PEM}_{6: 5,} \mathrm{PEM}_{11: 1+1}$ and $\mathrm{PEM}_{1615 .}$ respectively. in this Note). The IR spectra confirmed the formation of the PEM films (Figure la). The peak at $1478 \mathrm{~cm}^{-1}$ corresponded to the $-\mathrm{CH}_{2}-$ deformation in PDADMA. ${ }^{15}$ In the case of PSS, peaks at 1200 (doublet). 1126,1035 . and $1008 \mathrm{~cm}^{-1}$ were assigned as asymmetric vibration of $\mathrm{SO}_{3}{ }_{3}$. benzene ring-sulfur vibration. $\mathrm{Sym}$ metric vibration of $\mathrm{SO}_{3}^{-}$. and in-plane bending vibration of para-substituted benzene ring. respectively. ${ }^{16}$ After formation of the PEM films, the substrate was placed for $30 \mathrm{~min}$ in the $50-\mathrm{mM}$ silicic acid solution that had been made by adding $0.1-\mathrm{mM} \mathrm{HCl}$ solution of tetramethyl orthosilicate $(100 \mathrm{mM})$ to $100-1 \mathrm{mM}$ phosphate buffer $(\mathrm{pH} 5.5)$ with $\mathrm{L}: \mathrm{I}(\mathrm{v} / \mathrm{v})$ ratio. The silicification occurred on the entire area of the substrate. and the silica formation was confirmed by IR spectroscopy

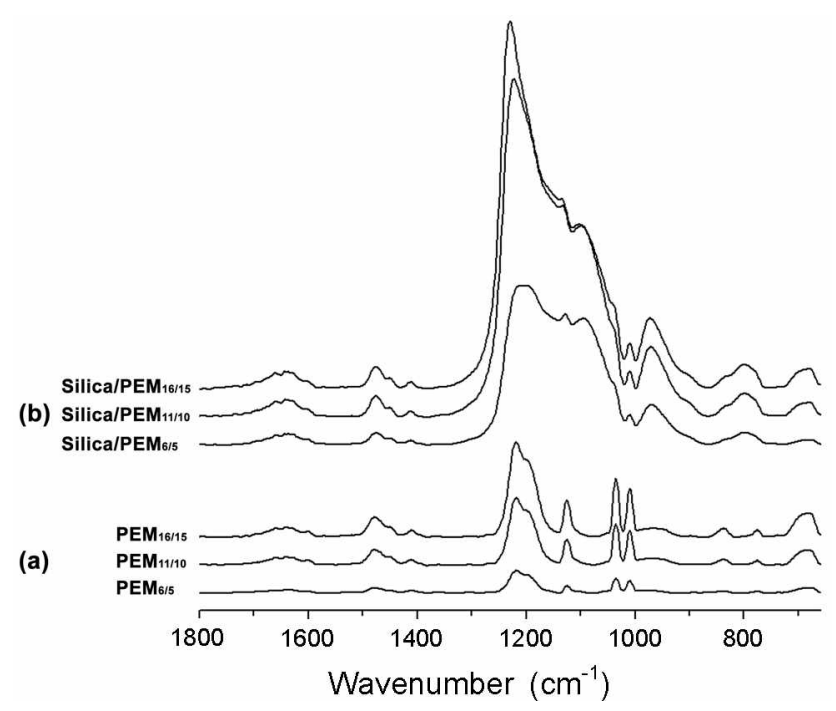

Figure 1. IR spectra of (a) PEM and (b) silica/PEM films. The subscript. N/M, indicates the number of PDADMA layers and the number of PSS lay ers in order. 


\section{PEM}
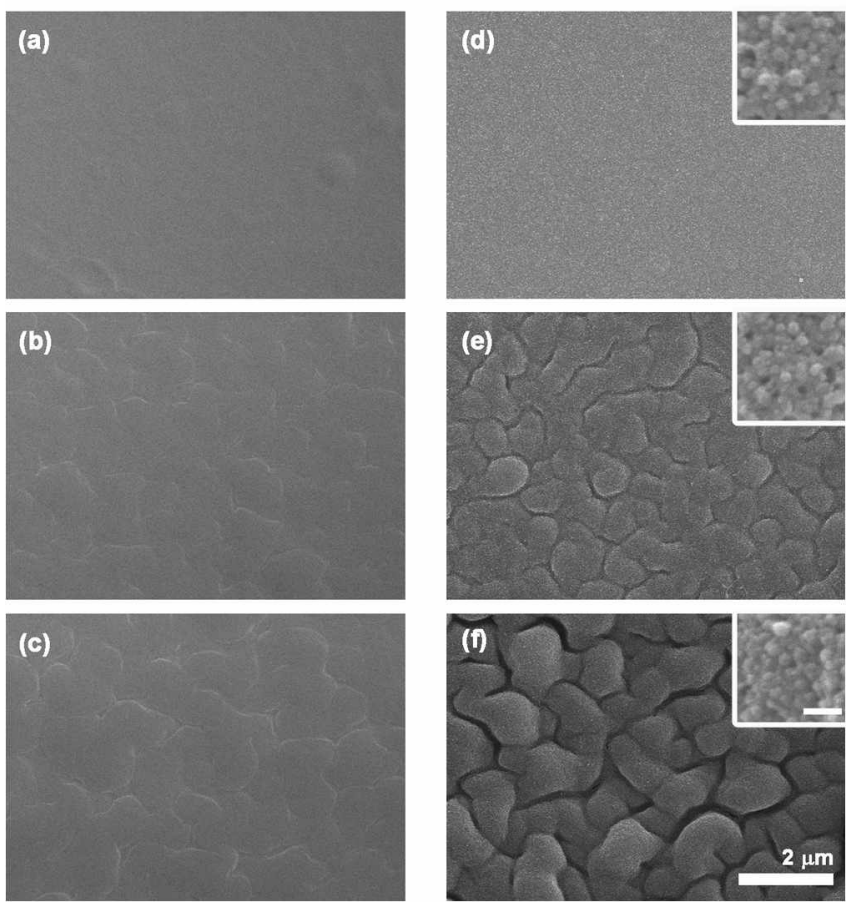

Figure 2. SEM micrographs of the PEM filns: (a) $\mathrm{PEM}_{\mathrm{n}}$, (b) $\mathrm{PEM}_{1: 10}$, and (c) PEM $\mathrm{P}_{16,15}$. SEM micrographs of the silica/PEM films: (d) silica/PEM $M_{5 ; 5}$, (e) silica/PEM $\mathrm{PM}_{1]: 10}$, and (f) silica/PEM $\mathrm{PM}_{15: 15}$. the scale bar of the inset is $50 \mathrm{rm}$.

(Figure Ib). After silicification, new peaks were observed at 1216 ( $\mathrm{Si}-\mathrm{O}-\mathrm{Si}$ asymmetric stretching). 969 ( $\mathrm{Si}^{-} \mathrm{O}^{-}$stretching). and $800 \mathrm{~cm}^{-1}$ (Si-O-Si symmetric stretching) ${ }^{56.12}$ The intensity of the corresponding peaks increased as the number of the multilayers did.

Scanning electron microscopy (SEM) was used to characterize the surface morphology of the PEM films (PEM $\mathrm{PEM}_{11: 10 \text {, and }} \mathrm{PEM}_{16: 15}$ ) and the resulting silica/PEM films (Figure 2). While PEMss was quite smooth (Figure 2a). $\mathrm{PEM}_{11: 10}$ showed mosaic-like stnictures at the micrometer scale. and the structures became more evident in the case of $\mathrm{PEM}_{1 \mathrm{~s}: 5}$ (Figure $2 \mathrm{~b}$ and $\mathrm{c}$ ). After silicification. the surface became bumpier and rougher. in comparison with the surface of the PEM films (Figure 2d-f). The high-magnification micrographs (insets of Figure 2d-f) showed that the surfaces were composed of silica nanoparticulates that had been observed in the previous studies of bio-inspired silicification. ${ }^{11,12.13}$

As a comparison. we attempted to generate the PEM films on the SAMs of dodecanethiol (DDT) over large area. In the case of DDT SAMs. although the PEM film was formed. the film tended to be peeled off from the surface with ease, especially during the washing step (Figure $3 a$ and b). In addition, it was observed that the PEM film contracted locally on the substrate in the course of silicification; uniform silica films were not formed due to the crack (Figure $3 \mathrm{c}$ and d). Based on this result. we used the MUA SAMs for further studies.

The ellipsometric thicknesses of the PEM films on the MUA SAMs were 34.5 (for PEM $\mathrm{P}_{(: 5}$ ), 177.2 (for $\mathrm{PEM}_{1]: 10}$ ). and 305.6 $\mathrm{Ium}$ (for PEM $\mathrm{P}_{1 \mathrm{~s} 15}$ ), respectively. As expected, the thickness of

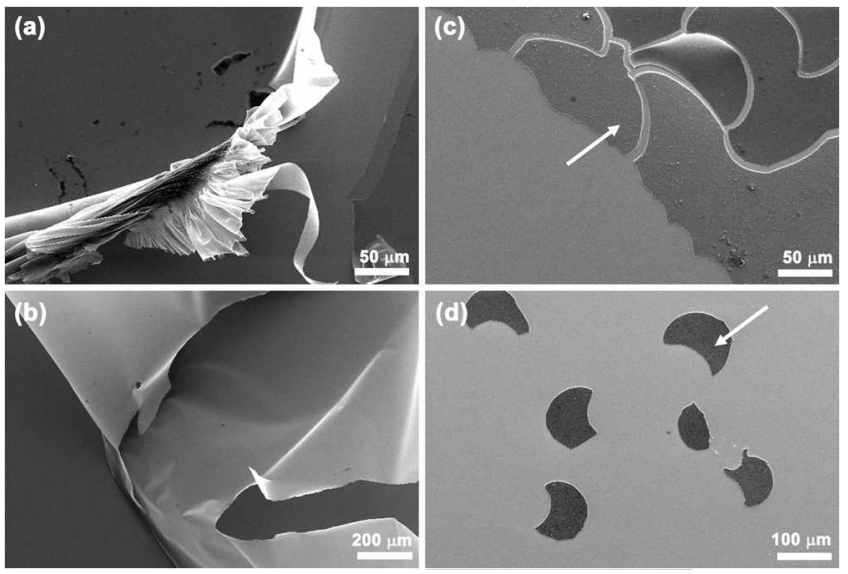

Figure 3. SEM micrographs of (a) $\mathrm{PEM}_{[1: 10}$ and (b) $\mathrm{PEM}_{16: 15}$ on the DDI SAMs. SEM micrographs of (c) ty pical silica/PEM $\mathrm{Pl}_{1010}$ and (d) typical silica $P E M_{1}$ s: on the LD' SAMs. 'l he arrows indicate silica/PEM films.

the PEM films increased as the number of the nultilayers did. The cross-sectional SEM micrographs indicated that the thicknesses of the PEM and silica/PEM films were controlled by the number of deposition steps (Figure 4). The average thicknesses were calculated by measuring the thicknesses of at least 50 points in the cross-sectional SEM micrograpls. The average thicknesses of the PEM films were 183.1 (for $\mathrm{PEM}_{11: 10}$ ) and $296.3 \mathrm{lum}$ (for $\mathrm{PEM}_{16: 15}$ ), which were in good agreement with the ellipsometric thicknesses ( 177.2 and $305.6 \mathrm{~nm}$ ). However. $\mathrm{PEM}_{\text {s }}$ was too thin to measure the thickness from the SEM micrograph. We. therefore. used the ellipsometeric thickness $\left(34.5 \mathrm{~nm}\right.$ ) for $\mathrm{PEM}_{6 ; 5}$, when drawing a bar graph (Figure $4 \mathrm{~g}$ ). The average thicknesses of the silica/PEM films (silica/PEM silica/PEM ${ }_{1: 110 \text {. and silica/PEM }}$ (1:5) were calculated to be 183.9. 767.1. and $1189.1 \mathrm{~nm}$, respectively. The thickness ratio of the silica/PEM films to the PEM ones was about $4-5$, which might imply that the assembled polyelectroly tes became loose and made a conplex with silica precursors in the silicification processes. Previously, we reported the silica film formation with tertiary amine-containing poly (2-dimethylaminoethyl methacrylate) (PDMAEMA) films generated by surfaceinitiated polymerization. ${ }^{96}$ In this case. the thickness ratio was about 2: the thickness of the PDMAEMA film was $70 \mathrm{~nm}$. and the thickness increased to $150 \mathrm{~nm}$ after silicification. Compared with the method of surface-initiated poly merization the $\mathrm{LbL}$ process led to a much higher increase in the thickness after silicification.

The thickness increase implied that the bio-inspired silicification was not linited to the top-most layer of PDADMA. but occurred in the entire layer of PDADMA/PSS films. As a comparison. we and others previously reported the formation of ultra-thin silica films $(<10 \mathrm{~nm})$ when bio-inspired silicification was catalyzed only by top-most functional groups. ${ }^{8 b .18}$ The presence of silica inside of the films was confirmed by energydispersive X-ray (EDX) spectroscopy (Figne 5). The EDX line-profiles for the cross-section of the dissected silica/PEM film indicated the presence of silica in the whole range of the film. and the elemental analy'sis showed that the compositions 
PEM

\section{Silica/PEM}
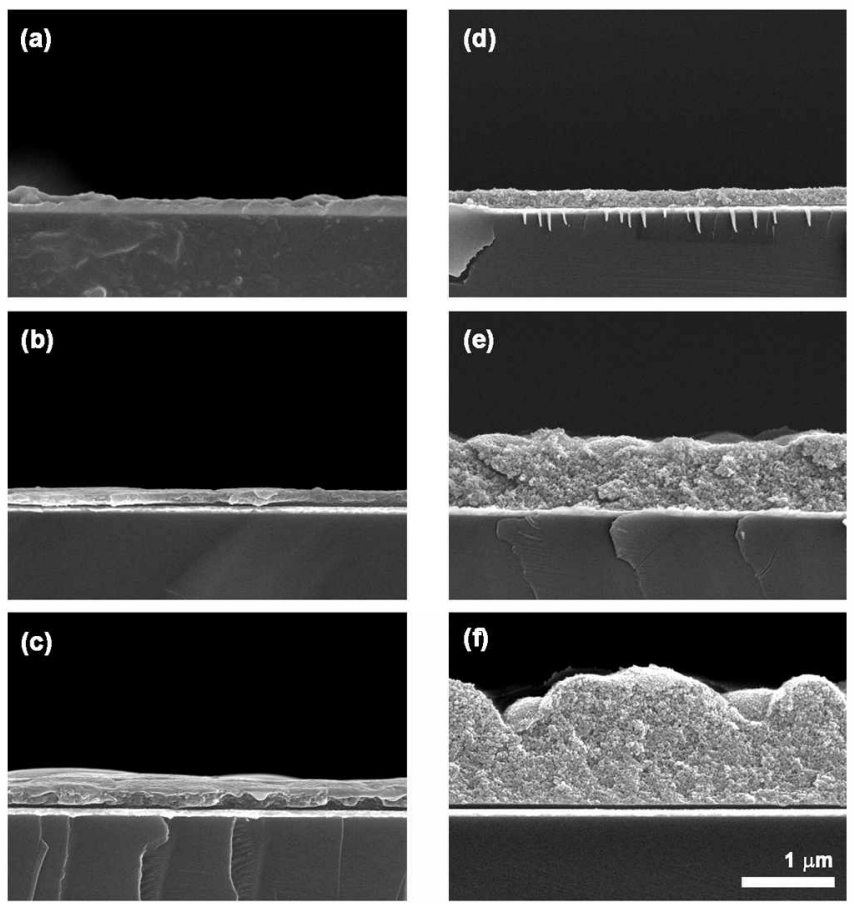

(g)

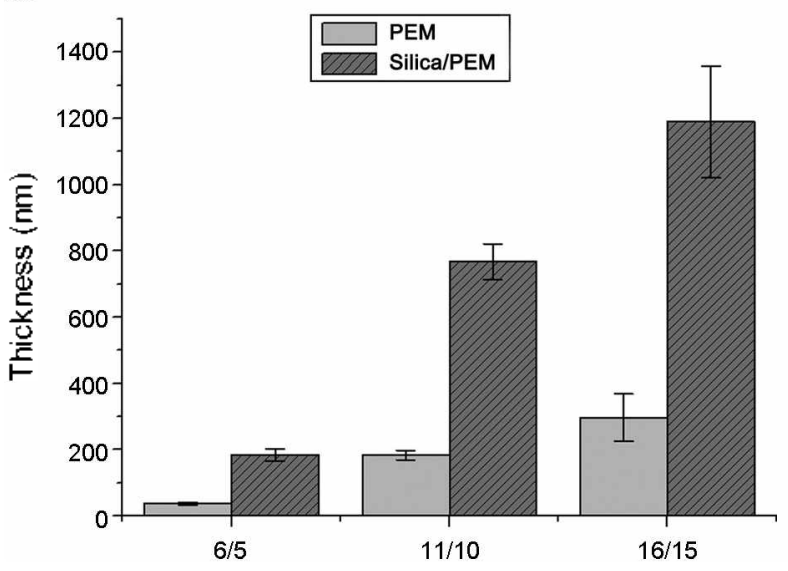

Number of deposition (PDADMA/PSS)

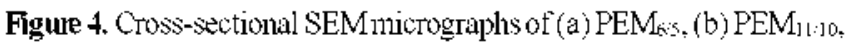
(c) $\mathrm{PEM}_{15: 15}$, (d) silica/PEM $\mathrm{PM}_{6.5}$, (e) silica/PEM $\mathrm{PM}_{1: 10}$, and (f) silica/ PEM $\left._{1}: 1 . \mathrm{g}\right)$ Average thicknesses of the PEM and silica/PEM films on the MUA SAMs.

of silica at the top layer were similar or nearly identical to those at the inner layer. Carbon was detected in the whole range of the silica/PEM film, which confinmed the hybrid nature of silica and polymers.

In summary. we formed silica (strictly speaking. silica/polymer hybrid) films over relatively large area by combining lay̌er-by-layer (LbL) self-assembly and bio-inspired silicification and characterized the resulting films by IR spectroscopy. scanning electron microscopy. ellipsometry, and energy-dispersive X-ray spectroscopy. The thickness increase was remarkable after silicification: about $\mathbf{4 - 5}$-fold increase was observed. Based on the characterizations in the present study along with

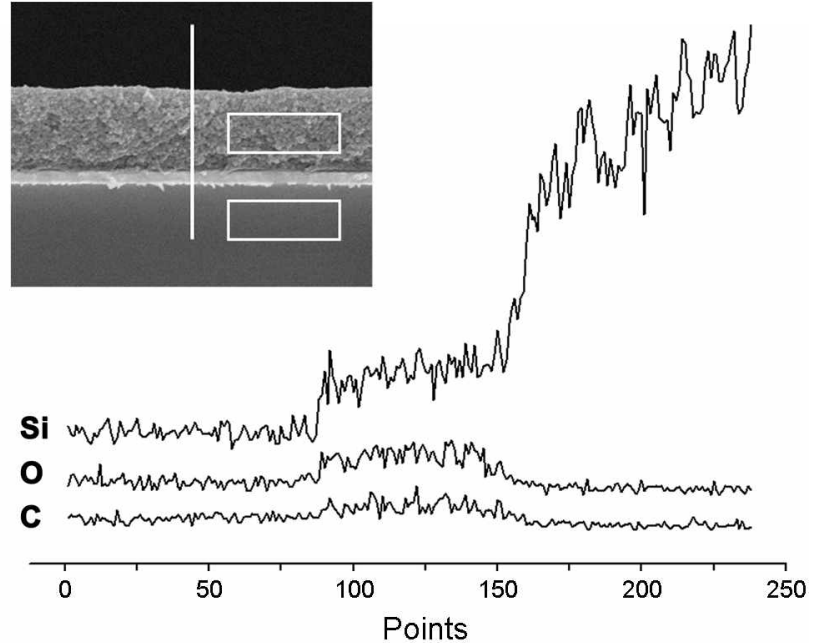

Si
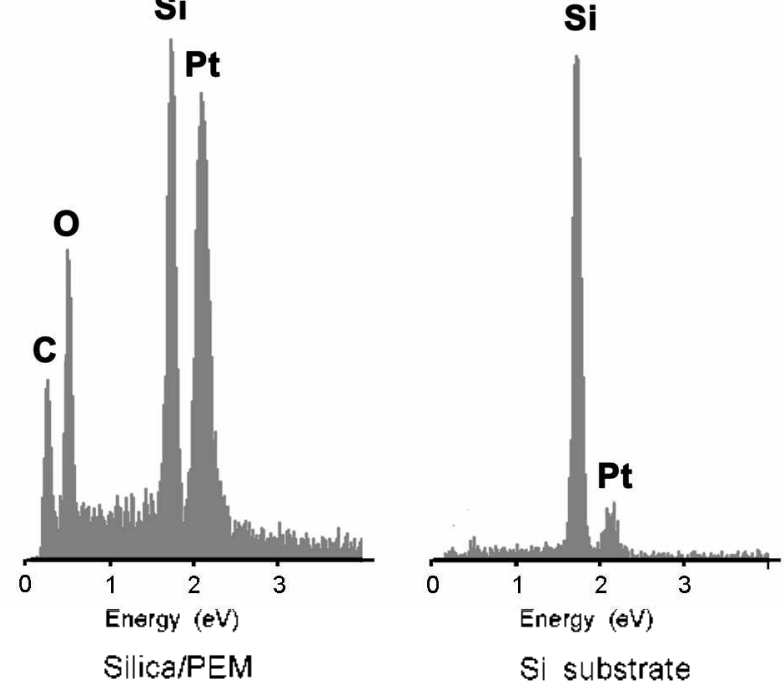

Figure 5. EDX line-profiles for the cross-section of silica/PEM $\mathrm{PL}_{\text {l:t। }}$ on the MUA SAMs, and the elemental analysis data for the top layer and the substrate. The $y$ axis is the intensity (arbitrary unit j.

our previous studies, we hypothesized that the chemical nature of non-covalently associated polyelectrolytes in the LbL assemblies played a role in the observed increase of the thickness. The surface density of the polyelectrolytes would not be as dense as that of the poly mers grafted by surface-initiated polymerization and the polyelectrolytes themselves would be relatively free locally. Therefore. the conformational change of the polyelectrolyte chains yielded more silica deposition (increase in the thickness). This hy pothesis could be supported by our previous report. The tightly associated, quaternized poly (2-dimethy laminoethyl methacry late) (PDMAEMA) film. generated by strong electrostatic interactions between the cationic polymer and counteranions of high charge density (such as $\mathrm{F}^{-}$). resulted in the formation of thin silica films. In contrast, loosely associated. quatenuized PDMAEMA films bearing a counteranion of lower charge density (such as $\mathrm{Br}^{-}$). had more flexibility for interacting and self-assembling with silicic acid derivatives. leading to the formation of thicker silica films. Detailed studies on the ș stem (LbL and subsequent 
silicification) will be our next research thrust.

Bio-inspired (or biomimetic) approach to the large-area formation of inorganic films has advantages and disadvantages. It does not require harsh reaction conditions, and is simple. fast. and biocompatible. Meanwhile. nature's selection of organic/inorganic hybrid materials requires cataly tic templates introduced onto the substrate surface for the film formation. In this work. we used the well-established LbL technique for this purpose, and demonstrated that the $\mathrm{LbL}$ technique could be combined with bio-inspired silicification. We envisioned that the LbL technique would be used for bio-inspired fabrication of other inorganic films. such as titanium oxide. and the inorganic films be generated by post-treatments, such as calcination.

\section{Experimental Section}

Materials. Gold-coated silicon wafers (with a titanium adhesion layer of $5 \mathrm{~nm}$ and thermally evaporated gold layer of $100 \mathrm{~mm}, \mathrm{~K}-\mathrm{MAC}$, Korea). 11-mercaptoundecanoic acid (MUA, 99\%, Aldrich), dodecanethiol (DDT. 99\%, Aldrich), poly (dially'dimethy lammonium chloride) (PDADMA. average $\mathrm{M}_{\mathrm{w}}$ : $100000 \sim 200000$. 20 wt $\%$ in $\mathrm{H}_{2} \mathrm{O}$. Aldrich), poly (sodium 4-styrenesulfonate) (PSS. average $\mathrm{M}_{w:}: 70000$, powder. Aldrich). lyy drochloric acid ( $\mathrm{HCl}, 35 \%$. Junsei). tetramethyl orthosilicate (TMOS. 99\% Aldrich), sodium phosphate dibasic ( $99 \%$ Aldrich). sodium dilhy'drogen phosphate ( $99 \%$. Aldrich) and absolute ethanol $(99.8 \%$. Merck) were used as received. Ultrapure water $(18.3 \mathrm{M} \Omega \cdot \mathrm{cm}$ ) from the Human Ultrapure System (Human Corp., Korea) was used

Synthetic Procedures. The gold substrate was immersed for $12 \mathrm{~h}$ in an ethanolic solution $(10 \mathrm{mM})$ of MUA or DDT for forming self-assembled monolayers (SAMs) on gold. An aqueous $\mathrm{NaCl}$ solution $(0.5 \mathrm{M})$ was used for preparing the PDADMA and PSS solutions. The final concentration of the solutions was $5 \mathrm{mg} / \mathrm{mL}$. The SAM-coated gold substrate $\left(6 \times 4 \mathrm{~cm}^{2}\right)$ was alternately immersed in $30 \mathrm{~mL}$ of the PDADMA solution and $30 \mathrm{~mL}$ of the PSS solution for 5 min each. After thoroughly washing the substrate with deionized water and drying it under a stream of argon. the PEM-coated substrate was placed in 2 $\mathrm{mL}$ of $50-\mathrm{mM}$ silicic acid solution. which had been independently prepared by stirring an $\mathrm{HCl}$ solution $(0.1 \mathrm{mM})$ of TMOS $(100 \mathrm{mM})$ at room temperature for $20 \mathrm{~min}$ and adding the resulting solution to aqueous sodium phosphate buffer $(100 \mathrm{mM}$. $\mathrm{pH} 5.5)$ with $1: 1(\mathrm{v} / \mathrm{v})$ ratio. After $30 \mathrm{~min}$, the substrate was taken out. washed with deionized water and ethanol. and dried under a stream of argon.

Characterizations. IR spectra were recorded on a Thermo Nicolet Nexus FT-IR spectrometer in a SAGA mode. Fieldemission scanning electron microscopy (FE-SEM) images and energy'-dispersive $\mathrm{X}$-ray (EDX) data were obtained by using an FEI XL FEG/SFEG microscope (FEI Co. Netherlands) equipped with EDX module. at an accelerating voltage of 10 $\mathrm{eV}$. All samples were sputter-coated with platinum. The film thickness was measured with a Gaertner L1 16s ellipsometer (Gaertner Scientific Corporation, USA) equipped with a He-Ne laser $(632.8 \mathrm{run})$ at a $70^{\circ}$ angle of incidence. A refractive index of 1.46 was used for all the films.
Aclnowledgments. This work was supported by the Korea Research Foundation Grant funded by the Korean Government (MOEHRD. KRF-2008-313-C00496). We also thank M. S. Hyun and M. H. Kim at the National Nanofab Center for the SEM analysis.

\section{Refelences}

1. (a) Bai, T.; Snively, C. M.; Delgass, W. N. Adv Mater 2002, 1t, 1546. (b) Ward T. H. Bashir, R. Peppas, N. A. J. Bioned. Hater Res. 2001, 56. 351. (c) Flemming. R. G.; Murphy, C. T.; Abrams, G. A.: Goodman, S. L.; Nealey, P. F. Biomaterials 1999. 20.573. (d) Chen. C. S.: Mrksich. M.: Huang. S.: Whitesides, (i. M.; Ingber; D. E. Science 1997, 276, 1425

2. (a) Chou, S. Y: Keimel, C.: Gu, J. Natum 2002, 177, 835. (b) Kambhampati, D. K.; Jakob, T. A. M.; Robertson, J. W.; Cai, M.; Pemberton. I. E.: Knoll. W Langmin 2001, 17, 1 169 (c) Rogers, T. A.: Mirkin. C. Mater. Res. Bull 2001, 26, 506 (d) Fodor, S. P. A. Science 1997, 277, 393. (e) Chou, S. Y. Krauss, P. R.; Renstrom, P. J. Science 1996, 272 85. (f) Chee, M.: Yang. R.: Hubbell E: Beno, A.; Huang, X. C.: Sten, D.: Winkler, J.: Lockhart, D. I.; Moris M. S. Fodor S. P. A Science 1996, 27t,610.

3. Petrucci, M. G. L.; Kakkar, A. K. Chent Hoter: 1999, 1, 269.

4. Rühe, J; Yarı, R.; Lee, J. S.; Köberle, P.; Knoll, W: Otfenhäusser, A. J. Biomater Sci. Polm Ed. 1999, 10,859

5. Cho. W. K.: Kang. S. M.: Kim. D. J.: Yang. S. H.: Choi. I. S Langmir 2006. 22. 11208

6. Brutchey, R. L.; Morse, D. E. Chem. Rev. 2008, 108, 4915

7. (a) Bäuerlein, E. Angew. Chem. Int Ed. 2003, 42, 614. (b) Sumper, M. Science 20012, 295, 2430. (c) Kröger, N.: Lorenz, S.: Brunner. E.: Sumper. M. Science 2002. 298. 584 . (d) Kröger. N.: Deutzmarn, R.; Bergsdorf, C.; Sumper, M. Proc. Natl. Acad. Sci. LSA 2000, 97, 14133. (e) Cha, T. N.; Shimizu, K.: Zhou, Y: Christiansen, S. C.: Clumelka, B. F.; Stucky, G. D.: Morse, D. E. Proc. Katl .tcad Sci. LS.1 1999, 96,361.

8. (a) Helmecke, O.: Hirsch, A.; Behrens, P.: Menzel, H. J. Coll. Interface Sci. 2008, 321, 44. (b) Coff́man, E. A, Melechtio, A. V.: Allison, D. P.: Simpson, M. L.: Doktyez, M. J. Langmin 2004, 20, 8431. (c) Brott, L. L.; Naik, R. R.: Pikas, D. I.; Kirkpatrick. S. M.: Tomlin. D. W.: Whitlock. P. W.: Clarson. S. J : Stone, M. O. Nature 2001, 113,291

9. (a) Yang, S. H., Kang, K. Choi, I. S. Chem. Asian J. 2008, 3, 2097. (b) Kim, D. I.; Lee, K.-B.; Lee, T. G.: Shon, H. K.; Kim. W.-T.; Paik, H.-j.: Choi, I. S. Smanl 2005, 1,992 (c) Kim, D. I: Lee, K. B.; Chi, Y. S.; Kim, W-I.; Paik, H.-j.; Choi, I. S. Langntuir 2004, 20, 7904

10. Wul, J-C.: Wans. Y.: Chen. C.-C.: Chang. Y.-C. Chem. Mater. 2008, 20,6148.

11. Laugel, N.; Hemmerle, J.: Porcel, C. Voegel, T.-C.: Schaaf, P. Ball, V. Langnuir 2007, 23, 3706 .

12. Yang, S. H. Choi, I. S. Chemt Asian J. 2009, \&, 382

13. (a) Anga, K.: Hill, J. P.: Ji, Q. Phws. Chem Chem. Phss 2007, 9. 2319 , (b) Hammond. P. T. idv Nater 2004, 16, 1271.

14. (a) Kong, B.; Kim, Y; Choi I. S. Bull. Konem Chem. Sac: 2008 29, 1843. (b) Choi, J.; Lee, Y. J.; Kang, H.; Han, J. W.; Noh, J. Bull Korean Chem Soc. 2008, 29, 1229

15. (a) Lul, J.: Zhang, T.; Xiao, C. J. Appl. Polm Sci. 2007, 106. 1972. (b) Mahdavi, H.; Haghani, E.; Malakian, B. Reac. Funct. Polym. 2006, 66, 1033. (c) Yang, G.; Zhang, L.; Feng, H. $J$. Membr. Sci. 1999, 161, 31.

16. (a) Yang, J. C.. Jablonsky, M. J.: Mays, J. W. Polnmer 2002, \$3, 5125. (b) Su, Z.; Li, X; Hsu, S. L. Macromolecules 1994, 27 , 287. (c) Orler, E. B.; Yontz, D. J.; Moore, R. B. Macromolecules 1993, 26, 5157. (d) Rigdahl, M.; Eisenberg, A. J. Polym. Sci. Pohm. Phs Ed 1981. 19, 1641. (e) Morton, M.: Fetters. L. I. Rubber Chem. Technol. 1975, $\$ 8,359$

17. Yang. S. H.; Park, J. H.; Cho, W. K.; Lee, H.-S.; Choi, I. S. Small 2009, 5, 1947-1951

18. Kang. S. M.; Lee, B. S.; Lee, S.-g.: Choi, I. S. Colloid Surf. A $2008,313-31+, 150$. 